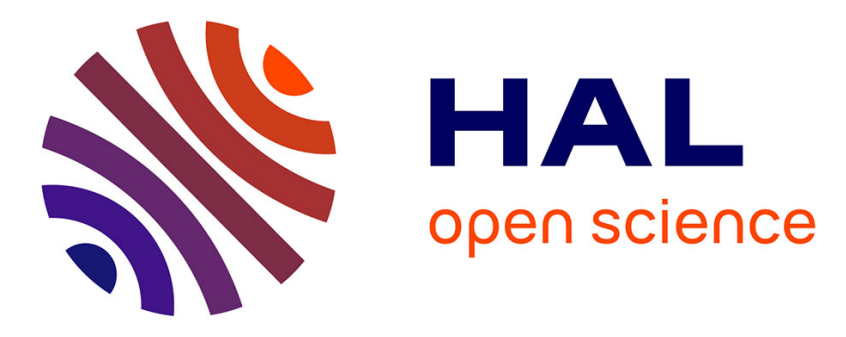

\title{
Surface-Assisted Self-Assembly of a Hydrogel by Proton Diffusion
}

\author{
Daniel Spitzer, Vincent Marichez, Georges J.M. Formon, Pol Besenius, \\ Thomas M. Hermans
}

\section{- To cite this version:}

Daniel Spitzer, Vincent Marichez, Georges J.M. Formon, Pol Besenius, Thomas M. Hermans. SurfaceAssisted Self-Assembly of a Hydrogel by Proton Diffusion. Angewandte Chemie International Edition, 2018, 57 (35), pp.11349-11353. 10.1002/anie.201806668 . hal-02296199

\section{HAL Id: hal-02296199 \\ https://hal.science/hal-02296199}

Submitted on 24 Sep 2019

HAL is a multi-disciplinary open access archive for the deposit and dissemination of scientific research documents, whether they are published or not. The documents may come from teaching and research institutions in France or abroad, or from public or private research centers.
L'archive ouverte pluridisciplinaire HAL, est destinée au dépôt et à la diffusion de documents scientifiques de niveau recherche, publiés ou non, émanant des établissements d'enseignement et de recherche français ou étrangers, des laboratoires publics ou privés. 


\section{Surface-assisted self-assembly of a hydrogel by proton diffusion}

Daniel Spitzer ${ }^{\dagger,[a]}$, Vincent Marichez ${ }^{\dagger,[b]}$, Georges J. M. Formon ${ }^{[b]}$, Pol Besenius ${ }^{*},[a]$, Thomas M. Hermans ${ }^{*},[\mathrm{~b}]$

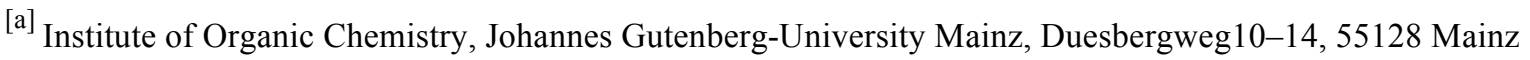

(Germany)

${ }^{[\mathrm{b}]}$ University of Strasbourg, CNRS, ISIS UMR 7006, 8 allée Gaspard Monge, 67000 Strasbourg(France)

$\dagger$ These authors contributed equaly to this work

* To whom correspondence should be addressed. E-mail: besenius@uni-mainz.de; $\underline{\text { hermans@unistra.fr }}$

Abstract: Controlling supramolecular growth at solid surfaces is of great importance to expand the scope of supramolecular materials. Here we describe a dendritic benzene-1,3,5tricarboxamide peptide conjugate whose assembly can be triggered by a $\mathrm{pH}$ jump. Stopped flow kinetics and mathematical modeling provide a quantitative understanding of the nucleation, elongation, and fragmentation behavior in solution. To assemble the molecule at a solid-liquid interface, we use proton diffusion from the bulk. The latter needs to be slower than the lag phase of nucleation in order to progressively grow a hydrogel outwards from the surface. Our method of surface-assisted self-assembly is generally applicable to other gelators, and can be used to create structured supramolecular materials.

Supramolecular structures are widely found in biological systems and in chemistry. ${ }^{[1]}$ In the former, microtubules and actin filaments have been studied intensively due to their crucial role in controlling cell migration and/or differentiation. ${ }^{[2]}$ In chemistry, in addition to the desire to mimic natural 1D fiber for medical applications, ${ }^{[3-5]}$ synthetic supramolecular polymers are also promising candidates for $\operatorname{smart}^{[6]}$ and self-healing ${ }^{[7,8]}$ materials or even molecular electronics. $^{[9,10]}$ Despite tremendous progress in controlling the size and shape of supramolecular structures by electrostatic interactions ${ }^{[11]}$, steric hindrance ${ }^{[12]}$ or stoichiometry, ${ }^{[13]}$ spatial control of the self-assembly process is still difficult to achieve. Up to now, only a few examples can be found as recently reviewed by Vigier-Carrière et al. ${ }^{[14]}$ Two main approaches can be used: 1) a seed layer deposited on a surface by adjusting the charge of the surface, ${ }^{[15,16]}$ its hydrophilicity, ${ }^{[17]}$ or by directly grafting monomers to trigger further selfassembly, ${ }^{[18]}$ or 2) by localized production of monomers, followed by gelation. The latter strategy was notably adopted by Cameron and Adams who used an electrode to locally decrease the $\mathrm{pH}$ (through oxidation of hydroquinone into 1,4-benzoquinone) thus activating the monomers whose self-assembly is then promoted. ${ }^{[19]}$ Electrochemical production of protons using patterned electrodes was also used by Payne to gain spatial control on the self-assembly 
of Fmoc protected amino acids. ${ }^{[20]}$ Others, like van Esch and Eelkema could control fiber formation and orientation by a $\mathrm{pH}$ gradient, ${ }^{[21]}$ further resorting to surface-confined acidic catalysis, ${ }^{[22]}$ while Ulijn paved the way of surface-confined enzyme catalysis, ${ }^{[23,24]}$ further developed by Vigier-Carrière et $\mathrm{al}^{[25]}$ together with Jierry ${ }^{[26]}$. In line with the first philosophy, here we describe the $\mathrm{pH}$-regulated self-assembly of an amphiphilic $\mathrm{C}_{3}$-symmetrical benzene1,3,5-tricarboxamide peptide conjugate (BTA-1, Figure 1A), and show how surface-assisted assembly is controlled inside microfluidic devices and from the surface of elastomer cubes. First, we study the (cooperative) mechanism of self-assembly in solution using stopped-flow kinetics and apply fitting procedures using temperature and concentration dependent mathematical models. Next, we utilize two proton releasing materials, either agarose or poly(dimethyl siloxane), PDMS, surfaces, which have significantly different kinetics of diffusion. To grow supramolecular (hydrogel) structures off the surface, the proton diffusion needs to be tuned and slow enough for nucleation to take place at the solid-liquid interface, in order to avoid nucleation and growth in solution. Our combined theoretical-experimental approach shows that investigating the kinetics of supramolecular self-assembly is key in manipulating lag times of nucleation and overall growth rates of supramolecular polymers, with the aim to develop surface-confined supramolecular materials. Our strategy does not require the addition of an external catalyst and is applicable to many $\mathrm{pH}$-responsive systems for the preparation of 3D-structured gels and surfaces.

We synthesized the dendritic peptide amphiphile BTA-1 analogously to previous methods (see SI, section 1). ${ }^{[27,28]}$ BTA-1 self-assembles through hydrogen bonding, $\pi-\pi$ stacking and desolvation of hydrophobic amino acids into densely packed supramolecular fibers with a diameter of $7 \mathrm{~nm}$ and more than $500 \mathrm{~nm}$ in length (Figure 1B, Supplementary Figure S2). The C-terminal dendritic carboxylic acids of the star-shaped peptide amphiphile introduces $\mathrm{pH}$ switchable properties into the molecular buildings blocks. ${ }^{[27]}$ At high $\mathrm{pH}$, the monomers of BTA-1 remain molecularly dissolved due to Coulomb repulsion of the anionic charges of the deprotonated carboxylates. Upon lowering the $\mathrm{pH}$, the carboxylates are protonated and alleviate the repulsive term which in turn induces a monomer to supramolecular polymer transition. While, the isolated carboxylic acids typically have a pKa of $4,{ }^{[29]}$ the thermodynamic driving force of supramolecular assembly leads to a strong shift in the apparent $\mathrm{pKa}$ value and transitions at a pH value of 5.6 (Supplementary Figure S3). From pH-dependent steady state circular dichroism (CD) spectroscopy experiments, it is safe to assume that BTA-1 is fully deprotonated at $\mathrm{pH}>6.0$ and fully protonated at $\mathrm{pH}<5.0$. 

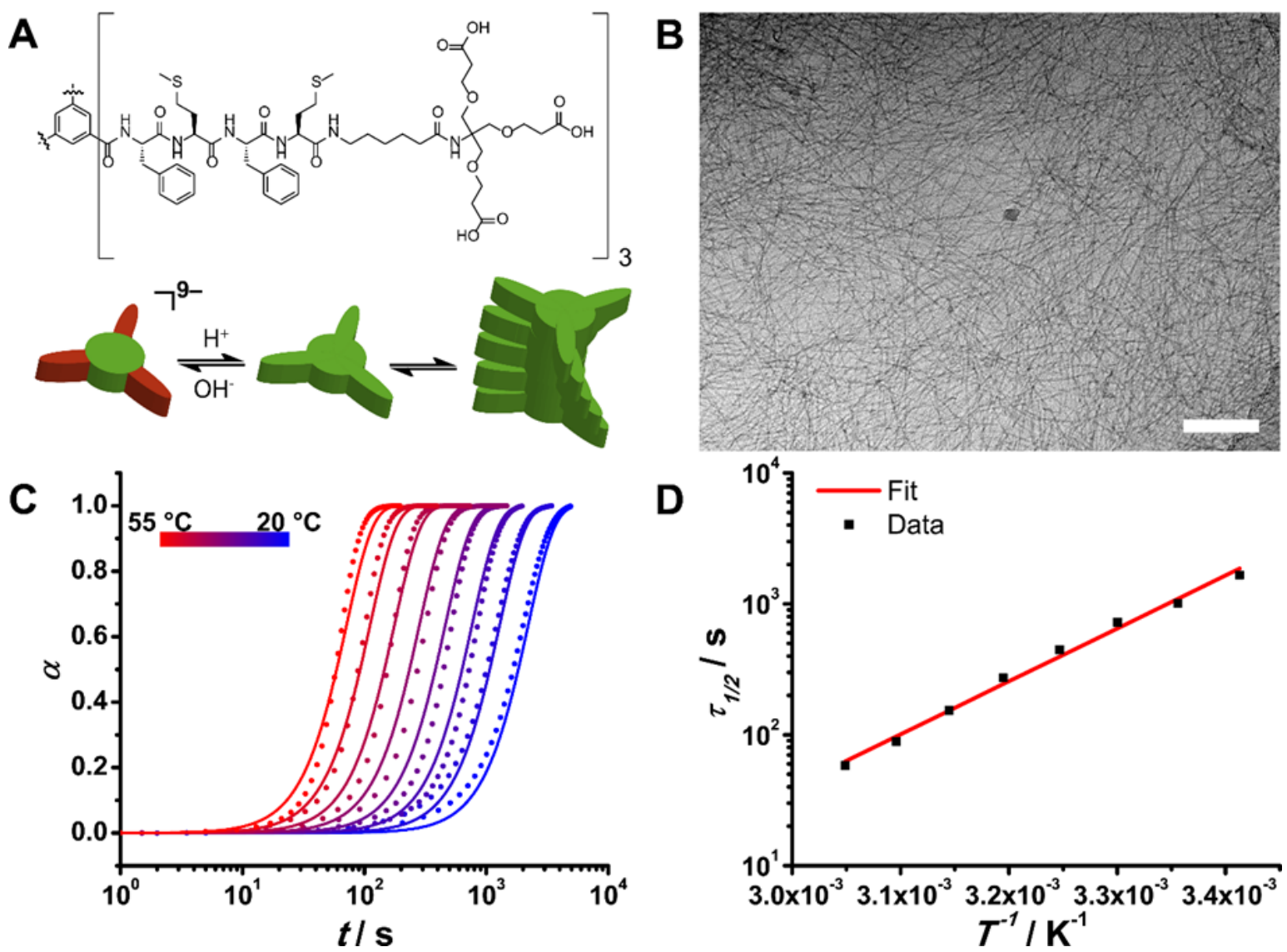

Figure 1: BTA-1 pH-triggered self-assembly. A) Structure of BTA-1. The tricarboxylic acid moieties can be protonated and deprotonated as a function of the $\mathrm{pH}$. At high $\mathrm{pH}(\mathrm{pH}>5.6)$, the monomer has 9 negative charges, and the resulting electrostatic repulsion between monomers prevents self-assembly. B) Cryo-TEM picture of the self-assembled fibers (at pH 5). Scale bar is $200 \mathrm{~nm}$. C) Temperature dependent self-assembly process of BTA-1 at $\mathrm{pH}$ 5. The dimensionless degree of polymerization $\alpha$ is shown versus time. Circles are data points observed by stopped-flow circular dichroism and the solid lines are the results of the global fitting of the supramolecular polymerization model including nucleation, elongation, fragmentation and Arrhenius equation to predict the rate constants. Adjusted $\mathrm{R}^{2}$ of 0.9848 . D) Half time of the polymerization as a function of the inverse of the temperature. The squares are the data points and the solid line is the result of the fitting with an Arrhenius type equation. The good fit (adjusted R2 = 0.9916) indicates that the kinetics of the supramolecular polymerization of the BTA-1 follows the Arrhenius law.

To investigate the self-assembly mechanism of BTA-1, we performed stopped-flow experiments, where $\mathrm{CD}$ intensity was monitored immediately after performing a $\mathrm{pH}$-jump. Since two plateau regions can be identified (i.e., $100 \%$ monomer, and $100 \%$ polymer), the latter intensity can be directly converted to the dimensionless degree of polymerization $\alpha$ (Figure 1C). Note, that we have previously studied neutral dendritic peptide amphiphiles at great length and correlated degree of order from CD spectroscopy with length of the 1D nanorods using electron microscopy, X- ray scattering and diffusion NMR spectroscopy. ${ }^{[30]}$ Recently, theoretical models that describe protein filament self-assembly (e.g., amyloids) have expanded 
beyond the conventional nucleation and elongation processes, and now include for example fragmentation and secondary nucleation. ${ }^{[31-35]}$ Knowles and co-workers have also included a temperature dependence in these models. ${ }^{[36]}$ Here, we use a modified version of the latter in the analyses that follow.

Concentration dependent series for $\mathrm{pH}$-jump induced supramolecular polymerization were performed, first at a constant temperature of $40{ }^{\circ} \mathrm{C}$ (Supplementary Figure S7). In addition, temperatures series (Figure 1C), at a constant monomer concentration of $80 \mu \mathrm{M}$ were carried out. The latter series provided better quality data, and global fitting using a single model (see below) was possible. The scaling exponent $\gamma$, which is the slope of the double-logarithmic plot of half-times versus initial monomer concentration (Supplementary Figure S5), can give us an initial insight of the underlying self-assembly mechanism. ${ }^{[35]}$ In our case, the scaling exponent $\gamma$ is -0.34 , which means that the mechanism involves more processes than just nucleation and elongation, for which $\gamma=-n_{c} / 2$ (with $n_{c}$ the critical nucleus size). The closest value of $\gamma$ (= $-0.5)$ points to a nucleation-elongation-fragmentation mechanism, which will be used from here on. ${ }^{[35]}$

The model was first individually fitted to the temperature and concentration series, and the nucleation-elongation-fragmentation model indeed yielded the best fit (Supplementary Figures S6 and S7). Given the nature of the data, i.e., unseeded experiments, the model is dependent on the combined rate constants $k_{p} k_{n}, k_{p} k_{f}$, and $k_{f} k_{d}$, where $k_{p}$ is the elongation, $k_{d}$ is the depolymerization, $k_{n}$ is the nucleation, and $k_{f}$ is the fragmentation rate constant. After individual fitting, the combined rate constant $k_{f} k_{d}$ was found to be more than 6 orders of magnitude smaller as compared to the two others $\left(k_{p} k_{n}, k_{p} k_{f}\right)$. For the case where $k_{d} \ll$ $k_{p} m_{0}$ (where $m_{0}$ is the initial monomer concentration) the depolymerization rate can be considered negligible. ${ }^{[35]}$ The ratio $k_{d} / k_{p} m_{0}$ was determined to be $\sim 10^{-2}$, so for subsequent global fitting, $k_{d}$ was considered to be zero to further reduce the number of free parameters. To understand the temperature dependency of the system, the half-times $\tau_{1 / 2}$ of the supramolecular polymerization were plotted as a function of the inverse of temperature and an Arrhenius-type equation was successfully fitted to the data (Figure 1D), indicating that the process follows Arrhenius behavior. A global fit of the model to the variable temperature data was then performed, including a nucleation-elongation-fragmentation mechanism and the combined rates predicted by the Arrhenius equation (see derivation of model in the SI, section $3)$. The free variables are the activation energies and the pre-exponential factors. Global 
minimization (Figure 1C, solid lines) with an adjusted $\mathrm{R}^{2}$ of 0.9848 , gives activation energies of $156.7 \pm 0.3 \mathrm{~kJ} \mathrm{~mol}^{-1}$ and $264.3 \pm 0.2 \mathrm{~kJ} \mathrm{~mol}^{-1}$ for the combined rates $k_{p} k_{n}$ and $k_{p} k_{f}$, respectively. The enthalpy and entropy of activation can be extracted from the Eyring plot or global fitting using the Eyring equation (Supplementary Figures S8 and S9 respectively). For the combined nucleation-elongation rate, $\Delta H_{n, e}^{\neq}$is $154.1 \pm 0.3 \mathrm{~kJ} \mathrm{~mol}^{-1}$ and $\Delta S_{n, e}^{\neq}$is $310.0 \pm$ $1.1 \mathrm{~J} \mathrm{~mol}^{-1} \mathrm{~K}^{-1}\left(T \Delta S_{n, e}^{\neq}=92.38 \pm 0.32 \mathrm{~kJ} \mathrm{~mol}^{-1}\right.$ at $\left.298 \mathrm{~K}\right)$. The entropy of activation is highly model dependent, so it is not easy to directly compare our values with those previously reported. ${ }^{[37]}$ Moreover, few temperature dependent kinetic studies exist, especially in water. However, our enthalpy and free energy of activation are in the same order of magnitude as compared to other studies of this type. ${ }^{[36,38]}$

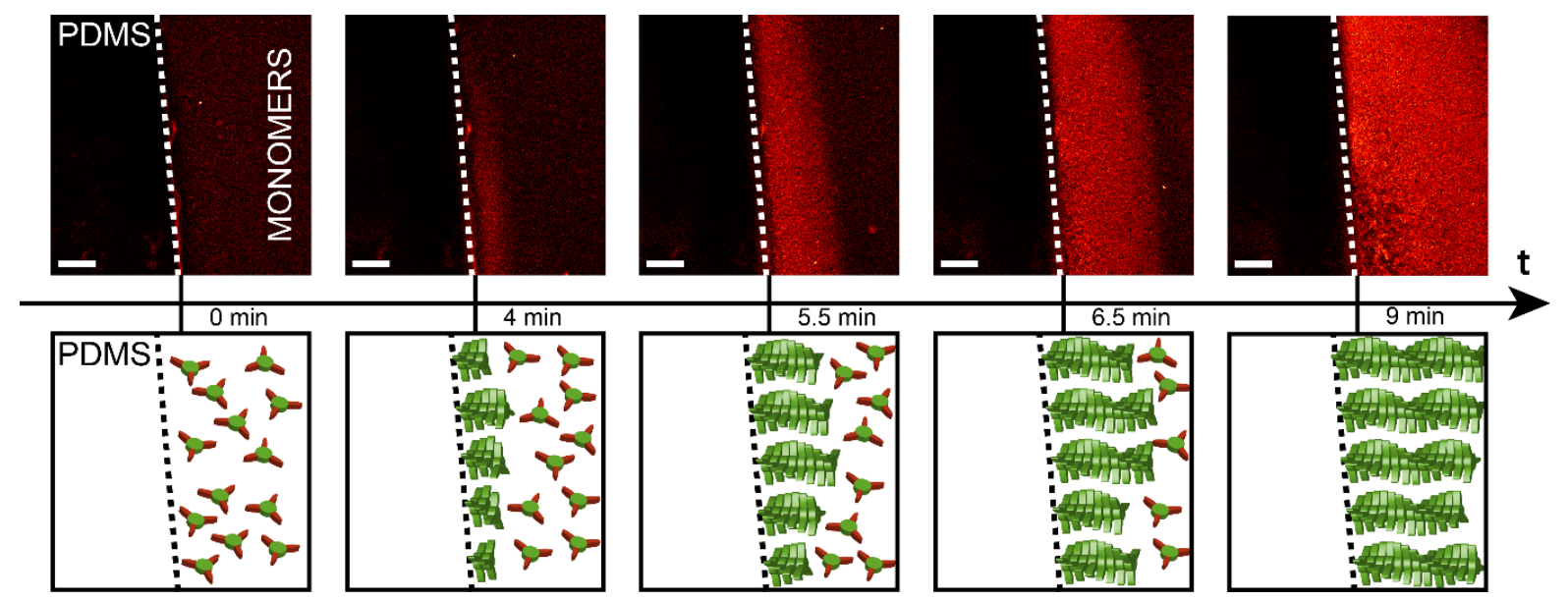

Figure 2: Surface-assisted self-assembly from a PDMS cube. Confocal microscopy of a $5 \mathrm{~mm}^{3}$ PDMS cube (screenshots of Supplementary Video 2), soaked in saturated $\mathrm{HCl}$ solution for 96 hours and subsequently dropped in a $160 \mu \mathrm{M}$ BTA-1 solution at pH 7.4 (monomers). After 4 min, one can see a thin hydrogel layer emerging from the PDMS block, followed by a propagating front of polymerization. Nile Red at $5 \mu \mathrm{M}$ is used as a dye. The scale bar is $200 \mu \mathrm{m}$.

The fact that this system fits with an Arrhenius-type model shows that the process is more enthalpy than entropy driven, which is confirmed by the Eyring plot (supplementary Figure S8). This is surprising for supramolecular polymers in water due to the hydrophobic effect, which has an entropic origin. ${ }^{[39]}$ We therefore conclude, that in the case of BTA-1 the selfassembly is driven by H-bonding of the peptide side arms, confirmed by the high B-sheet content observed in CD spectra (Supplementary Figure S3A), while hydrophobic interactions play a secondary role. ${ }^{[39]}$ Being able to model this process combining well-known amyloid growth models and the Arrhenius equation, also shows that this easily implemented model can be applied to study synthetic supramolecular polymerization, which opens new avenues to understand temperature dependent self-assembly of artificial molecules. 
To gain spatial control over the self-assembly process, we decided to combine proton diffusion from a solid substrate with pH-triggered BTA-1 self-assembly in order to induce nucleation at (or close to) the solid-liquid interface followed by hydrogel growth from the surface. From our kinetic studies, we know that typical lag times of nucleation at room temperature are $\sim 100 \mathrm{~s}$ (see Figure 1C). One can imagine that very fast proton diffusion is undesired if aiming for a surface-assisted self-assembly, since the supramolecular polymerization is not able to keep up. Indeed, when we placed 5-10 $\mathrm{mm}^{3}$ agarose gel cubes, soaked in concentrated $\mathrm{HCl}_{\text {,aq }}$ for $96 \mathrm{~h}$, in a $160 \mu \mathrm{M}$ solution of BTA-1 at $\mathrm{pH}=7.4$, the entire solution rapidly became cloudy followed by precipitation (cf. Supporting Movie 1). Neither supramolecular structures at the surface nor gelation was observed. However, if $5-10 \mathrm{~mm}^{3}$ cubes of poly(dimethyl siloxane), PDMS, soaked in concentrated $\mathrm{HCl}_{\text {,aq }}$ for $96 \mathrm{~h}$ were used, a propagating front of supramolecular polymerization / gelation was observed (Figure 2 and Supplementary Videos 2 and 3). After a few minutes, when the protons start to diffuse out of the PDMS, BTA-1 monomers get activated and start self-assembling at the surface forming a growing hydrogel layer on the PDMS cube. The gel front moves at $\sim 3 \mu \mathrm{m} \mathrm{s}^{-1}$, suggesting that the proton diffusion from PDMS is rate limiting (see below). The formed hydrogel initially looks completely uniform (at the resolution of confocal microscopy), but after $\sim 9 \min$ (Figure 2, Supplementary Videos 2 and 3) signs of fiber bundling / gel coarsening start to appear. Surprisingly, our surface-assisted self-assembly procedure, more than providing spatial resolution, yields bundles of fibers (imaged by electron microscopy in Supplementary Figure S10) much bigger than those observed when nucleation occurs in solution (cf. Figure 1B). Heterogeneous nucleation from the surface thus seems to be significantly different from homogeneous nucleation for BTA-1 and leads to distinct supramolecular architectures. 

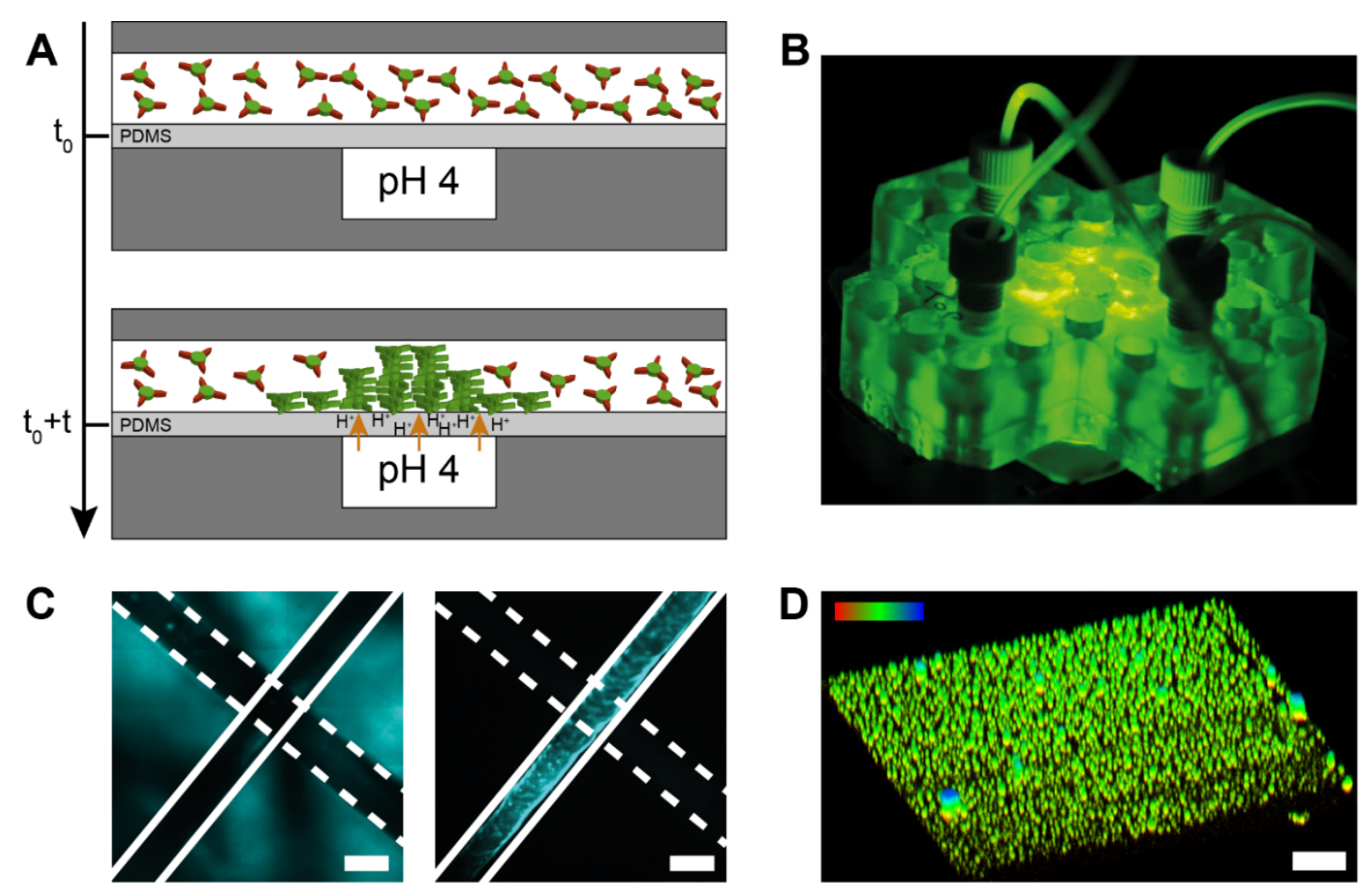

Figure 3: Microfluidic device to control surface-assisted self-assembly. A) Side view of the microfluidic device. It consists of 2 perpendicular channels on top of each other and separated by a $100 \mu \mathrm{m}$ PDMS membrane. The bottom channel is filled with a $\mathrm{pH} 4$ buffer and the top one is filled a $160 \mu \mathrm{M}$ BTA-1 solution at $\mathrm{pH} 7.4$ (monomers). At $\mathrm{t}=\mathrm{t} 0+\mathrm{t}$, we start the flow of the buffer channel at $500 \mu \mathrm{L} \mathrm{min}^{-1}$ while the monomer channel is at rest (i.e., no flow). The protons start diffusing through the membrane and eventually reach the other channel, activating the monomers in solution that start growing on the membrane. The self-assembly occurs at the intersection of the 2 channels B) Picture of the 3D-printed microfluidic device 75 by 75 by $13 \mathrm{~mm}$ on the microscope stage. C) Transmitted light (left) and fluorescence image (right) of the intersection between the two channels taken after the experiment. Only the top channel shows fluorescence intensity which indicates that the BTA-1 monomers self-assemble in response to the $\mathrm{pH}$-gradient. Scale bar is $500 \mu \mathrm{m}$. D) 3D-reconstructed image (from a z-slice confocal experiment) of the membrane after $2 \mathrm{~h}$ proton diffusion. Supramolecular $\sim 2 \mu \mathrm{m}$ spheroids were formed at the PDMS surface. Scale bar is $10 \mu \mathrm{m}$. The top left colour gradient indicates the height in the $\mathrm{z}-$ axis, where red is 0 and blue is $10 \mu \mathrm{m}$. Note that the image is elongated in the z-direction (up) due to the point spread function. Nile Red at $5 \mu \mathrm{M}$ is used as a dye for all these experiments.

To be able to investigate the early stages of gelation at the PDMS surface, we used a homebuilt microfluidic device consisting of two 3D-printed parts that clamp a thin $100 \mu \mathrm{m}$ PDMS membrane (Figure 3A,B). The membrane is flanked by two perpendicular rectangular channels (500 by $800 \mu \mathrm{m}$ ). The top channel (cf. Figure $2 \mathrm{~A}$ ) is first filled with a $160 \mu \mathrm{M}$ BTA-1 solution at pH 7.4 (monomers), after which the flow is stopped. The bottom (perpendicular) channel contains a continuous flow at $500 \mu \mathrm{L} \mathrm{min}{ }^{-1}$ of $\mathrm{pH} 4$ potassium hydrogen phthalate (KHP) buffer. 
After 5 minutes, protons start diffusing through the membrane and the fluorescence intensity (due to the presence of solvatochromic Nile red which intercalates in the hydrophobic domains of the supramolecular polymers) in the channel containing the monomers gradually increases, indicating that the self-assembly is occurring. This is more in agreement with the water diffusion in PDMS, which has been reported to be in the order of $10^{-9} \mathrm{~m}^{2} \mathrm{~s}^{-1},{ }^{[40]}$ rather than proton diffusion in water, which at $\sim 9 \cdot 10^{-9} \mathrm{~m}^{2} \mathrm{~s}^{-1}$ is an order of magnitude faster. ${ }^{[41]}$ After 2 hours, the experiment was stopped and the PDMS membrane was removed and imaged using confocal fluorescence microscopy (Figure 3D). The latter was done to use a high magnification oil-immersion objective, which cannot be used inside the 3D-printed microfluidic device. Small $\sim 2 \mu \mathrm{m}$ assemblies were observed (Figure 3D, and middle slice in Supplementary Figure S11). It therefore seems that in the first stages of nucleation and growth of BTA-1 starts from the latter spherical assemblies, before growing into a more uniform hydrogel observed on the PDMS cubes with confocal and electron microscopy.

In conclusion, we have shown that investigating the kinetics of $\mathrm{pH}$-regulated supramolecular polymerization in water using stopped flow experiments and fitting the data with a broadly applicable concentration and temperature dependent mathematical model provides access to important kinetic parameters, including the lag time (of nucleation), and overall growth rates (here due to elongation and fragmentation). We further utilized two synthetic proton releasing solid substrates to grow supramolecular (hydrogel) structures from the solid-liquid interface. In order for surface-assisted self-assembly triggered by proton diffusion to work, the rate of diffusion needs to be slower than the nucleation rate, so supramolecular polymer structures form close to the surface and can grow gradually outwards. Our approach can be applied to many other pH-responsive (small molecule) self-assembling systems and (hydro)gelators in order to obtain surface functionalization and patterning. An interesting implementation would be to use different molecular gelators sequentially to obtain $3 \mathrm{D}$-structured functional gels. ${ }^{[14]}$ 


\section{Acknowledgements}

TMH would like to acknowledge funding from FP7-PEOPLE-2013-CIG 'NON-EQ-SA' (631350), ERC-2017-STG 'Life-Cycle' (757910), LabEx CSC project Controlling supramolecular assembly by "tunable anti-cooperativity", GF received funding from Ministère de l'Education Nationale, de l'Enseignement supérieur et de la Recherche. VM was funded by IdEx attractivité Centrosome centering by dissipative self-organization. D.S. and P.B. acknowledge financial support from the University of Mainz and the Center for INnovative and Emerging MAterials (CINEMA).

\section{Conflict of interest}

The authors declare no conflict of interest.

\section{References}

[1] T. Aida, E. W. Meijer, S. I. Stupp, Science 2012, 335, 813-817.

[2] D. A. Fletcher, R. D. Mullins, Nature 2010, 463, 485-492.

[3] V. M. Tysseling-Mattiace, V. Sahni, K. L. Niece, D. Birch, C. Czeisler, M. G. Fehlings, S. I. Stupp, J. A. Kessler, J. Neurosci. 2008, 28, 3814-3823.

[4] K. Rajangam, H. A. Behanna, M. J. Hui, X. Han, J. F. Hulvat, J. W. Lomasney, S. I. Stupp, Nano Lett. 2006, 6, 2086-2090.

[5] R. N. Shah, N. A. Shah, M. M. D. R. Lim, C. Hsieh, G. Nuber, S. I. Stupp, Proc. Natl. Acad. Sci. 2010, 107, 3293-3298.

[6] A. H. Gelebart, D. Jan Mulder, M. Varga, A. Konya, G. Vantomme, E. W. Meijer, R. L. B. Selinger, D. J. Broer, Nature 2017, 546, 632-636.

[7] A. Feula, X. Tang, I. Giannakopoulos, A. M. Chippindale, I. W. Hamley, F. Greco, C. P. Buckley, C. R. Siviour, W. Hayes, Chem. Sci. 2016, 7, 4291-4300.

[8] A. W. Bosman, R. P. Sijbesma, E. W. Meijer, Mater. Today 2004, 7, 34-39.

[9] Y. Yamamoto, T. Fukushima, Y. Suna, N. Ishii, A. Saeki, S. Seki, S. Tagawa, M. Taniguchi, T. Kawai, T. Aida, Science 2006, 314, 1761-1764.

[10] M. Sofos, J. Goldberger, D. A. Stone, J. E. Allen, Q. Ma, D. J. Herman, W. W. Tsai, L. J. Lauhon, S. I. Stupp, Nat. Mater. 2009, 8, 68-75.

[11] P. Besenius, G. Portale, P. H. H. Bomans, H. M. Janssen, A. R. A. Palmans, E. W. Meijer, Proc. Natl. Acad. Sci. 2010, 107, 17888-17893.

[12] S. I. Stupp, V. LeBonheur, K. Walker, L. S. Li, K. E. Huggins, M. Keser, A. Amstutz, Science 1997, 276, 384-389. 
[13] Q.-F. Sun, J. Iwasa, D. Ogawa, Y. Ishido, S. Sato, T. Ozeki, Y. Sei, K. Yamaguchi, M. Fujita, Science 2010, 328, 1144-1147.

[14] C. Vigier-Carrière, F. Boulmedais, P. Schaaf, L. Jierry, Angew. Chemie - Int. Ed. 2018, 57, 1448-1456.

[15] B. Xing, C.-W. Yu, K.-H. Chow, P.-L. Ho, D. Fu, B. Xu, J. Am. Chem. Soc. 2002, $124,14846-14847$.

[16] J. C. Tiller, Angew. Chemie Int. Ed. 2003, 42, 3072-3075.

[17] M. G. F. Angelerou, A. Sabri, R. Creasey, P. Angelerou, M. Marlow, M. Zelzer, Chem. Commun. 2016, 52, 4298-4300.

[18] Y. Liu, X.-D. Xu, J.-X. Chen, H. Cheng, X.-Z. Zhang, R.-X. Zhuo, Colloids Surf. B. Biointerfaces 2011, 87, 192-197.

[19] E. K. Johnson, D. J. Adams, P. J. Cameron, J. Am. Chem. Soc. 2010, 132, 5130-5136.

[20] Y. Liu, E. Kim, R. V. Ulijn, W. E. Bentley, G. F. Payne, Adv. Funct. Mater. 2011, 21, $1575-1580$.

[21] I. Ziemecka, G. J. M. Koper, A. G. L. Olive, J. H. van Esch, Soft Matter 2013, 9, $1556-1561$.

[22] A. G. L. Olive, N. H. Abdullah, I. Ziemecka, E. Mendes, R. Eelkema, J. H. van Esch, Angew. Chemie Int. Ed. 2014, 53, 4132-4136.

[23] R. J. Williams, A. M. Smith, R. Collins, N. Hodson, A. K. Das, R. V. Ulijn, Nat. Nanotechnol. 2009, 4, 19-24.

[24] M. P. Conte, K. H. A. Lau, R. V. Ulijn, ACS Appl. Mater. Interfaces 2017, 9, 32663271 .

[25] C. Vigier-Carrière, T. Garnier, D. Wagner, P. Lavalle, M. Rabineau, J. Hemmerlé, B. Senger, P. Schaaf, F. Boulmedais, L. Jierry, Angew. Chemie - Int. Ed. 2015, 54, 1019810201.

[26] J. Rodon Fores, M. L. Martinez Mendez, X. Mao, D. Wagner, M. Schmutz, M. Rabineau, P. Lavalle, P. Schaaf, F. Boulmedais, L. Jierry, Angew. Chemie - Int. Ed. 2017, 56, 15984-15988.

[27] M. von Gröning, I. de Feijter, M. C. A. Stuart, I. K. Voets, P. Besenius, J. Mater. Chem. B 2013, 1, 2008.

[28] D. Spitzer, L. L. Rodrigues, D. Straßburger, M. Mezger, P. Besenius, Angew. Chemie - Int. Ed. 2017, 56, 15461-15465.

[29] T. Joon Cho, R. A. Zangmeister, R. I. MacCuspie, A. K. Patri, V. A. Hackley, Chem. Mater. 2011, 23, 2665-2676. 
[30] R. Appel, J. Fuchs, S. M. Tyrrell, P. A. Korevaar, M. C. A. Stuart, I. K. Voets, M. Schönhoff, P. Besenius, Chem. - A Eur. J. 2015, 21, 19257-19264.

[31] T. P. J. Knowles, C. A. Waudby, G. L. Devlin, S. I. A. Cohen, A. Aguzzi, M. Vendruscolo, E. M. Terentjev, M. E. Welland, C. M. Dobson, Science 2009, 326, 1533-1537.

[32] S. I. A. Cohen, M. Vendruscolo, M. E. Welland, C. M. Dobson, E. M. Terentjev, T. P. J. Knowles, J. Chem. Phys. 2011, 135, DOI 10.1063/1.3608916.

[33] S. I. A. Cohen, M. Vendruscolo, C. M. Dobson, T. P. J. Knowles, J. Chem. Phys. 2011, 135, DOI 10.1063/1.3608917.

[34] S. I. A. Cohen, M. Vendruscolo, C. M. Dobson, T. P. J. Knowles, J. Chem. Phys. 2011, 135, DOI 10.1063/1.3608918.

[35] G. Meisl, J. B. Kirkegaard, P. Arosio, T. C. T. Michaels, M. Vendruscolo, C. M. Dobson, S. Linse, T. P. J. Knowles, Nat. Protoc. 2016, 11, 252-272.

[36] S. I. A. Cohen, R. Cukalevski, T. C. T. Michaels, A. Šarić, M. Törnquist, M. Vendruscolo, C. M. Dobson, A. K. Buell, T. P. J. Knowles, S. Linse, Nat. Chem. 2018 2018, $10,523-532$.

[37] A. K. Buell, A. Dhulesia, D. A. White, T. P. J. Knowles, C. M. Dobson, M. E. Welland, Angew. Chemie Int. Ed. 2012, 51, 5247-5251.

[38] J. Baram, H. Weissman, B. Rybtchinski, J. Phys. Chem. B 2014, 118, 12068-12073.

[39] E. Krieg, M. M. C. Bastings, P. Besenius, B. Rybtchinski, Chem. Rev. 2016, 116, 2414-2477.

[40] J. M. Watson, M. G. Baron, J. Memb. Sci. 1996, 110, 47-57.

[41] D. R. Lide, Handbook of Chemistry and Physics, CRC Press, 2003. 